\title{
Prospects of Application of Dual-Fuel Combined Cycle Gas Turbine Units
}

\author{
Olesya Borush ${ }^{1 *}$, Pavel Shchinnikov ${ }^{1}$, and Anna Zueva ${ }^{1}$ \\ ${ }^{1}$ Novosibirsk State Technical University, Prospekt K. Marksa, 20, Novosibirsk, Russia
}

\begin{abstract}
Dual-fuel combined cycle gas turbine units, including power units on the parallel scheme with predominant coal combustion are considered in the paper. The basic equations for determining the energy efficiency of dual-fuel combined-cycle power units are described. The interdependence of the efficiency of the gas turbine and steam turbine parts of the combined-cycle plant for the efficiency of the combined-cycle plant with a variable binary coefficient is presented. It is shown that $55-56 \%$ efficiency is achievable for parallel type combined cycle gas turbine units $\mathrm{T}$ with predominant solid fuel combustion on the basis of this interdependence between efficiency and binary coefficient. Comparison of competitiveness in the ratio of fuel prices for gas / coal with traditional coal technology and theoretical rejected combined cycle gas turbine units with an efficiency of $60 \%$ for dual-fuel combined cycle gas turbine units with the implementation of the Rankine cycle for subcritical (13 MPa) and supercritical (24 MPa) steam parameters is carried out. It is shown that the dual-fuel combined cycle gas turbine units are preferable to traditional coal steam turbine power units in the case when the ratio of the price of fuel does not exceed 5 , binary rejected combined cycle gas turbine units, when the ratio of the prices by more 0,5 .
\end{abstract}

\section{Introduction}

Analysis of the Russian energy sector over the past decade shows that the country's energy sector is characterized by a steady increase in capacity from 200 GW in 2007 [1-3] to $244 \mathrm{GW}$ in 2017 [4]. It should be noted that the structure of the generation has not changed much over the past period, which indicates the proportional development of the market for each type of installation (Fig. 1).

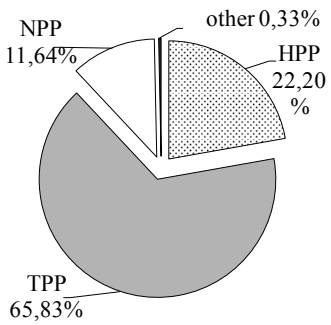

a) 2007

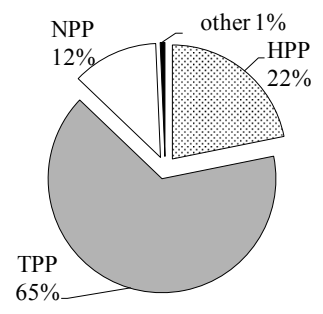

b) 2017
Fig. 1. Structure of the generation in Russia: TPP - Thermal power plant, NPP - Nuclear power plant, HPP - Hydroelectric power plant.

At the same time, the structure of the fuel balance of the regional energy sector has changed in the direction of increasing the share of gas (Fig. 2), in consequence of that CCGT are much wider used in domestic energy [5].

However, the introduction of purely binary steam and gas installations remains impractical in areas with coal energy, such as the Siberian Federal district, the far
Eastern Federal district and partially the Ural Federal district.

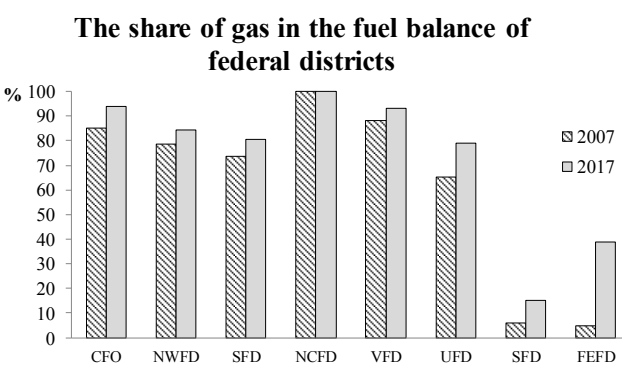

a)

The share of coal in the fuel balance of federal districts

$\square 2007$

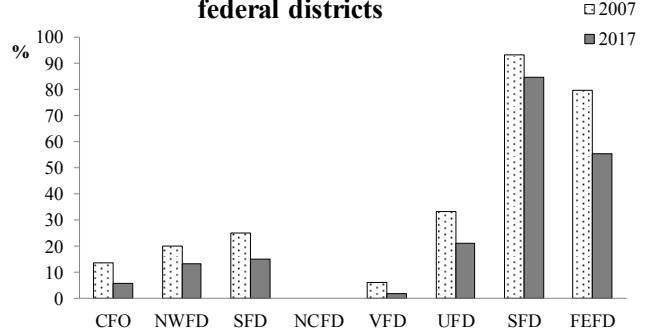

b)

Fig. 2. Structure of the fuel balance in Russia: CFO - Central Federal District, NWFD - North-West Federal District, SFD

- Southern Federal District, NCFD - North Caucasian Federal District, VFD - Volga Federal District, . SFD Siberian Federal District, Far Eastern Federal District.

The introduction of dual-fuel steam-gas plants (CCGT) is proposed to consider as one of the options for 
the long-term development of energy in such regions, in which one type of fuel is used for the combustion chamber, and to provide additional energy supply another. These settings allow you to engage the coal to combined-cycle technology and to ensure the most efficient from using this type of fuel

\section{Method of evaluation of energy efficiency of dual fuel CCGT}

There are various schemes of dual-fuel CCGT (Fig. 3), for example, with the utilization of exhaust gases in the GTU as an oxidizer (due to the presence of about $18 \%$ of oxygen) in the furnace of a steam coal boiler, or as a coolant in a special heat exchanger included to the thermal scheme of the power unit; with the discharge of the heat flow of the exhaust gases in the GTU into the network installation (to the special gas network heater) with the displacement of the steam turbine corresponding thermal selections while maintaining the thermal scheme of the power unit; with the utilization of exhaust gases in a gas network heater installed in parallel with the network heater for heating water by selecting a steam turbine; CCGT with coal gasification $[6,7]$. The choice of the most favorable parameters and

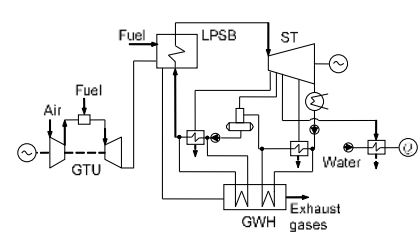

a)

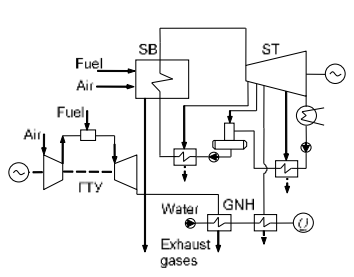

c)

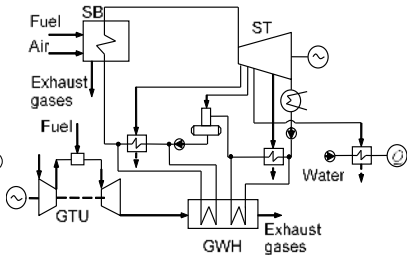

b)

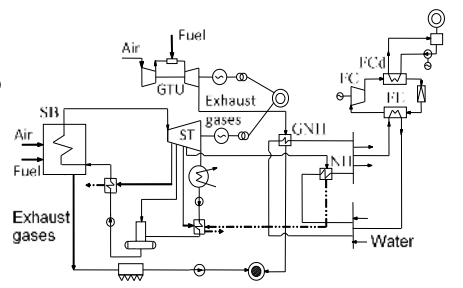

d)
Fig. 3. Schemes of dual-fuel combined-cycle plants with a lowpressure steam generator (a); with gas water heater (b); with gas heater (c); with gas heater and freon thermotransformer (d): LPSB - low pressure steam boiler; SB - steam boiler; ST steam turbine; GTU - gas turbine unit; GWH - gas and water heater; GNH - gas network heater; FCd - freon condenser; FC freon compressor; FE - freon evaporator.

schemes of CCGT is due to the technology prospects and high efficiency and to the variety of possible combinations of both commercially available units and installations, and the possibility of designing new equipment. In addition to the above schemes, it is proposed to consider a variant of dual-fuel combined cycle gas turbine units (CCGT) with a parallel scheme, Fig. 4
Table 1. Main technical specification of CCGT-370 with afterburning

\begin{tabular}{|l|c|}
\hline \multicolumn{1}{|c|}{ Indicator } & Value \\
\hline GTU capacity, mW & 130 \\
\hline STP capacity, mW & 240 \\
\hline CCGT capacity, mW & 370 \\
\hline $\begin{array}{l}\text { GTU net efficiency } \\
\text { (with air temperature }-5{ }^{\circ} \mathrm{C} \text { ), } \%\end{array}$ & 38,7 \\
\hline Sharp steam pressure, $\mathrm{MPa}$ & 12,8 \\
\hline Sharp steam temperature, ${ }^{\circ} \mathrm{C}$ & 540 \\
\hline The pressure of the reheated steam, MPa & 2,7 \\
\hline The temperature of the reheated, ${ }^{\circ} \mathrm{C}$ & 500 \\
\hline Exhaust gas temperature, ${ }^{\circ} \mathrm{C}$ & 514 \\
\hline CCGT net efficiency, $\%$ & 46,5 \\
\hline $\begin{array}{l}\text { CCGT specific fuel consumption, } \\
\text { kg.ef } / \mathrm{kWh}\end{array}$ & 0,264 \\
\hline $\begin{array}{l}\text { Equivalent fuel specific consumption for } \\
\text { GTU, } \mathrm{kg} . e f / \mathrm{kWh}\end{array}$ & 0,318 \\
\hline $\begin{array}{l}\text { Natural fuel consumption } \\
\text { (gas with } Q_{\mathrm{H}}^{\mathrm{p}}=36 \mathrm{MJ} / \mathrm{m} 3 \text { ), thousand } \mathrm{m}^{3} / \mathrm{h}\end{array}$ & 33,6 \\
\hline $\begin{array}{l}\text { Conventional fuel consumption for STP, } \\
\text { t.ef/h }\end{array}$ & 53,4 \\
\hline $\begin{array}{l}\text { Natural fuel consumption } \\
\text { (coal with } Q_{\mathrm{H}}^{\mathrm{p}}=22 \mathrm{MJ} / \mathrm{kg} \text { ), } \mathrm{t} / \mathrm{h}\end{array}$ & 71,2 \\
\hline Binary coefficient & 0,44 \\
\hline
\end{tabular}

Fig. 4. I nermodynamic diagram (a) and dual-tuel $\mathrm{C} C \mathrm{G} I \mathrm{l}$ with coal afterburning thermal scheme (b): GTU - gas turbine unit; $\mathrm{SB}$ - steam boiler; HR - heat recovery boiler; D- deaerator; CP - condensate pump; FW - feed pump; $Q_{S U P}^{\mathrm{GTU}}, Q_{\mathrm{SUP}}^{\mathrm{STP}}-$ supplying to GTU and STP heat; $Q_{\text {remove }}^{\mathrm{GTU}}, Q_{\text {remove }}^{\text {STP }}-$ removing from GTU and STP heat; NGTU, NSTP - electric capacity of GTU and STP.

Thermal energy is supplied to two places of thermodynamic cycle in the dual-fuel combined cycle gas turbine units (CCGT), Fig.4a. On the one hand - to the burner with using natural gas, on another hand - to the steam boiler (processes FW-0, SH1-SH2), where we can use coal. [8-13]. High temperature pressure sharp steam is achieved in the steam boiler (SB) due to the fuel combustion (in particular coal). The CCGT with coal combustion makes it possible to get the cyclic process efficiency, which is not achievable in other power generation technologies applied to this fuel type. [12].

The turbine exhaust gas goes into the heat recovery steam generator to generate steam, which then goes to the steam turbine plant (STP). This technology allows to increase the total efficiency of the unit, fig.4. Steam flows from the steam boiler and heat recovery steam generator go to the turbine in parallel. These schemes are called parallel.

Net efficiency for the gas turbine unit and steam turbine plant:

$$
\begin{gathered}
\eta_{G T U}^{n e t}=\eta_{G T U} \eta_{\text {los }}^{G T U} \eta_{\text {aux }}^{G T U} ; \\
\eta_{S T P}^{n e t}=\eta_{S T P} \eta_{b} \eta_{S T} \eta_{e m} \eta_{\text {aux }}^{S T P}=\eta_{S T P} \eta_{\text {los }}^{S T P} \eta_{\text {aux }}^{S T P} .
\end{gathered}
$$

Where $\eta_{b}$ steam boiler and heat recovery steam 
generator efficiency; $\eta_{S T}, \eta_{e m}-$ steam turbine and electromechanical efficiency; $\eta_{l o s}^{G T U}, \eta_{l o s}^{S T P}-$ irreversible losses efficiency; $\eta_{\text {aux }}^{G T U}, \eta_{\text {los }}^{S T P}-$ consideration of

Table 2. Efficiency and fuel consumption by different plants with their installed capacity of $300 \mathrm{MW}$

\begin{tabular}{|l|c|c|c|}
\hline \multicolumn{1}{|c|}{ Indicator* } & STP & CCGT(d) & CCGT(b) \\
\hline $\begin{array}{l}\text { CCGT net } \\
\text { efficiency** }\end{array}$ & $0,4 / 0,42$ & $0,49 / 0,52$ & 0,6 \\
\hline \multicolumn{4}{|c|}{ Specific consumption of reference fuel, kgfe /(kWh) } \\
\hline Coal & $0,307 / 0,292$ & - & - \\
\hline Gas & - & - & 0,205 \\
\hline Second consumption of reference gross fuel, kgfe/s \\
\hline Coal & $23,8 / 22,7$ & $12,74 / 11,9$ & - \\
\hline Gas & - & $7,21 / 7,21$ & 16,8 \\
\hline The annual consumption of reference fuel, thousand tons.fe \\
\hline Coal & $428 / 408$ & $229 / 214$ & - \\
\hline Gas & - & $129 / 129$ & 302 \\
\hline Sum & $42 / 408$ & $358 / 343$ & 302 \\
\hline $\begin{array}{l}\text { Gas/coal price } \\
\text { ratio with equal } \\
\text { economic } \\
\text { efficiency ** }\end{array}$ & $\begin{array}{l}\text { STP and } \\
\text { CCGT(d) }\end{array}$ & $\begin{array}{l}\text { CCGT(d) } \\
\text { and } \\
\text { CCGT(b) }\end{array}$ & CCGT(b) \\
\cline { 2 - 4 } & $5,09 / 4,82$ & $0,53 / 0,49$ & $1,41 / 1,35$ \\
\hline
\end{tabular}

* index "d" - dual-fuel;" b " - binary;

** in numerator for $24 \mathrm{MPa}$, in denominator for $13 \mathrm{MPa}$

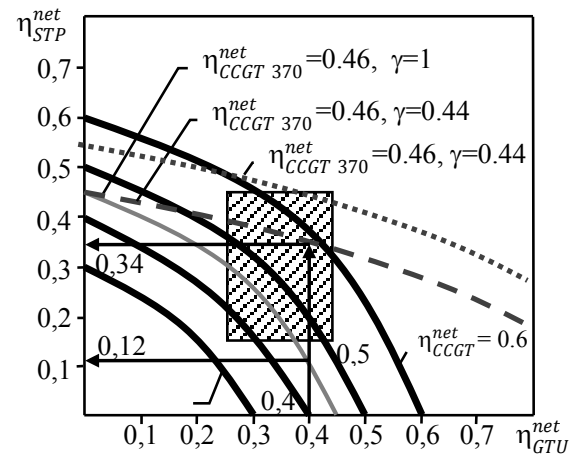

Fig. 5. Interdependence $\eta_{S T P}^{\text {net }}$ от $\eta_{G T U}^{\text {net }}$ for different $\eta_{C C G T}^{\text {net }}$.

auxiliaries.

Whereupon, by using method [14]:

$$
\begin{gathered}
\eta_{C C G T}^{\text {net }}=\eta_{G T U} \eta_{\text {los }}^{G T U} \eta_{\text {aux }}^{G T U}\left(1-\eta_{\text {STP }} \eta_{\text {los }}^{S T P} \eta_{\text {aux }}^{S T P}\right) \gamma+ \\
+\eta_{S T P} \eta_{\text {los }}^{S T P} \eta_{\text {aux }}^{S T P}
\end{gathered}
$$

here $\gamma$ - binary coefficient:

$$
\gamma=\frac{Q_{\text {sup }}^{G T U}}{Q_{\text {sup }}^{C C G T}}=\frac{Q_{\text {sup }}^{G T U}}{Q_{\text {sup }}^{G T U}+Q_{\text {sup }}^{S T P}} .
$$

If $\eta_{\text {los }}^{G T U}=\eta_{l o s}^{S T P}=0.9$, and auxiliaries efficiency $\eta_{l o s}^{G T U}$ $=\eta_{\text {los }}^{S T P}=0.95$, then equation for binary CCGT with afterburning efficiency:

$$
\eta_{C C G T}^{n e t}=0.855 \eta_{G T U}\left(1-0.855 \eta_{S T P}\right) \gamma+0.855 \eta_{S T P} \text {. }
$$

This interdependence shows that CCGT efficiency coefficient at level $46 \%$ for GTU with efficiency $40 \%$ might be achieved by efficiency coefficient of STP $12 \%$ if the binary coefficient is one (Fig. 5) [15].

The analysis of figure 5 shows that for the parallel-type CCGT with the predominant solid fuel combustion, the efficiency at the level of $55-56 \%$ are achievable.

\section{Compare dual fuel parallel type CCGT with auxiliary STP on coal and binary CCGT}

Estimations of fuel flow rate for CCGT without afterburning $(\gamma=1)$ and with afterburning $(\gamma=0,44)$ under comparable conditions for a $370 \mathrm{MW}$ unit (gas price is 5500 rubles/thousand $\mathrm{m} 3$ and coal 2250 rubles/t) show that CCGT with afterburning saves more than 2 times gas, in the case of using coal in a steam boiler. (Table. 1).

This provides savings of more than 500 million rubles per year due to the difference in the cost of different types of fuels.

Given the difference in the cost of the two types of fuel for the considered dual-fuel CCGT, it is of interest to identify the competitiveness zone of different technologies in the ratio of fuel prices. Further, dual-fuel CCGT, binary CCGT (on gas) and traditional coal-fired CCGT are taken into consideration.

The ratio of gas price to coal

$$
\delta=\mathrm{P}_{\text {gas }} / \mathrm{P}_{\text {coal }},
$$

which delivers equal efficacy of dual-fuel technology from «clean» coal and «clean» gas technologies with maximum efficiency is determined as part of the comparison. Meanwhile the compared variants are given to comparable form in terms of installed capacity and output. The task is analytical, it is designed to identify the prospects of application of the compared technologies in the context of changes in fuel prices.

For this purpose, each technology is compared in pairs by annual fuel consumption. In this case, the capital investment in the units is not taken into account. The calculations are carried out in reference fuel with the installed capacity of each of the compared units of 300 MW at 5000 hours of use.

For each pair, the total annual consumption of coal and gas is determined by two technologies, then the interrelation is determined

$$
\delta=\sum_{i=1}^{2} B_{i \text { coal }}^{\text {yeal }} / \sum_{i=1}^{2} B_{i \text { gas }}^{\text {year }} .
$$

Two different cycles were compared. In the first case, the Rankine cycle is performed on supercritical steam parameters (24 MPa), in the second - on subcritical (13 $\mathrm{MPa})$, Table 2.

Parameter $\delta$ is a term that describes the price ratio between gas and coal, in which both technologies equally in the costs of fuel with equal electricity supply 
to the consumer.

By comparing the STP-CCGT pair (b), an increase of the gas price leads to an increase of $\delta$, hence the coal technology is preferable.

Comparison of STP-CCGT(d) pair is as follows. If gas is more expensive than coal less than $\delta$ times $\left(\delta_{\text {fact }}<\delta_{\text {calc. }}\right)$, the dual-fuel technology becomes preferable.

For a pair of CCGT(d)-CCGT(b): dual fuel technology is preferable in the case the gas is more expensive than coal more than $\delta$ times $\left(\delta_{\text {fact }}>\delta_{\text {calc }}\right)$.

\section{Conclusions}

The structure of the regional energy fuel balance over the past decade has changed in the direction of increasing the share of gas, with the largest scale of the gasification process of the territory provided in the far Eastern Federal district, where the share of gas increased from 5 to $39 \%$. In the context of changes in the region fuel balance with reduce the cost of production improving the efficiency of the technology continues to be relevant.

Some variants of CCGT operating simultaneously on two types of fuel: coal and gas are considered. From the results of the calculation we can see that:

- the efficiency values at level of 55-56\% are achievable for parallel type CCGT with predominant solid fuel combustion.

- Dual-fuel parallel type CCGT is preferable to traditional pulverized coal power units in case the ratio of fuel prices of gas/coal does not exceed 5.

- Dual-fuel parallel type CCGT is preferable to binary discharge CCGT when the ratio of fuel prices gas/coal more than 0,49-0,53.

Thus, the development of dual-fuel combined cycle gas turbine units' technologies are a promising direction in the modernization and technical re-equipment of existing power plants in the coal regions.

\section{References}

1. P.A. Shchinnikov, Energy and heat engineering. The structure of Russian power generating capacity, 11, 5-33 (2007) (in Russian)

2. P.A. Shchinnikov, Perspective thermal power stations. Singularities and results of research (NSTU Publishing house, Novosibirsk, 2007) (in Russian)

3. B.F. Vainzikher, Expert, The invisible hand in the energy sector, 25, 42-47 (2007) (in Russian)

4. V.S. Zhukov, Bulletin of Peoples' Friendship University of Russia. Series: Economy, Power engineering in Russia: state and prospects for modernization, 2, 18-28 (2012) (in Russian)

5 . General layout of objects of Russian power until 2035.

URL: http://static.government.ru/media/files/zzvuuhfa2f3OJIK 8AzKVsXrGIbW8ENGp.pdf (Accessed on: Dec.15, 2018) (in Russian)

6. G.V. Nozdrenko, P.A. Shchinnikov, Complex exergy analysis of power units of heat power plants based on new technologies (NSTU Publisher, Novosibirsk, 2009) (in Russian)

7. A.M. Kler, N.P. Dekanova, E.A. Tyurina [et al.], Thermal power systems: Optimization studies (Nauka Publisher, Novosibirsk, 2005) (in Russian)

8. Gas turbine power units. Works CKTI Ed. By Yu.G. Korsova, M.M. Ivashchenko. (St. Petersburg, 2002) (in Russian)

9. G.V. Nozdrenko, O.K. Grigoryeva, A.A. Frantseva, Thermophysics and Aeromechanics Combined heat supply from CHP with gas grid heaters and thermal transformers, 19, 3 (75), 391-397 (2012) (in Russian)

10. Yu. K. Petrenia Conf. Power Engineering of Russia New Solutions, The history of the development of combined cycle in Russia. Development prospects (2006) URL: $\quad \mathrm{http}: / / \mathrm{www} . c 0 m b i e n e r g y . r u /$ stat/900-Istoriyaparogazovogo-cikla-v-Rossii-Perspektivy-razvitiya (Accessed on Jul. 03, 2018).

11. S.V. Tsanev, V.D. Burov, A.S. Zemtsov, O.S., Osyka Gas turbine power units, (Publishing House MEI, Moscow 2011) (in Russian)

12.P.A. Schinnikov, G.V. Nozdrenko, I.V. Borodikhin, O.V. Borush, Power engineering: research, equipment, technology, Combined-cycle plant using primery solid fuel, 3-4, (2007) (in Russian)

13.P.A. Shchinnikov, G.V. Nozdrenko, A.A. Lovtsov "Energy-saving combined-cycle technology for the reconstruction of pulverized-type CHP", Thermophysics and Aeromechanics, vol. 9, no. 3, pp. 445-449, 2002. (in Russian)

14. N.I. Kirsanova Energy and heat engineering Thermodynamics of combined cycles, 20 (2016) (in Russian)

15. P.A. Shchinnikov, V.A. Krugbelyi, P.V. Belyavskaya Conf. Energy Saving in Urban Economy, Energy, Industry, Efficiency of CCPP with coal afterburning, 1, 21-22

(in Russian) 